\title{
ERK, Akt, and STAT5 are differentially activated by the two growth hormone receptor subtypes of a teleost fish (Oncorhynchus mykiss)
}

\section{Jeffrey D. Kittilson, Evan Jones and Mark A. Sheridan*}

Department of Biological Sciences, North Dakota State University, Fargo, ND, USA

\section{Edited by:}

Yong Zhu, East Carolina University, USA

\section{Reviewed by:}

Brian M. Shewchuk, East Carolina University, USA

Christopher H. K. Cheng, The Chinese University of Hong Kong, Hong Kong

*Correspondence:

Mark A. Sheridan, Department of Biological Sciences, North Dakota State University, P.O. Box 6050,

Department 2715, Fargo, ND

58108-6050, USA.

e-mail:mark.sheridan@ndsu.edu
Previously, we found that the teleost fish, rainbow trout, possesses two growth hormone receptor (GHR) subtypes that display distinct ligand-binding and agonist-induced regulation features. In this study, we used Chinese hamster ovary-K1 cells stably transfected individually with the two trout GHR subtypes, GHR1 and GHR2, to elucidate receptor-effector pathway linkages. Growth hormone $(\mathrm{GH})$ stimulated rapid $(5-10 \mathrm{~min})$ phosphorylation of ERK, Akt, JAk2, and STAT5 in both GHR1- and GHR2-expressing cells; however; STAT5 was activated to a greater extent through GHR1 than through GHR2, whereas ERK and Akt were activated to a greater through GHR2 than through GHR1. Although blockade of the ERK pathway had no effect on the activation of Akt, inhibition of PI3K-Akt partially prevented activation of ERK, suggesting cross-talk between the ERK and PI3K-Akt pathways. JAK2 inhibition completely blocked activation of ERK, Akt, and STAT5, suggesting that all of these pathways link to GHR1 and GHR2 via JAK2. These findings establish important receptor-effector pathway linkages and suggest that the GHR subtypes of teleost fish may be functionally distinct.

\section{Keywords: growth hormone, signal transduction, U0126, LY294002}

\section{INTRODUCTION}

Growth hormone (GH) regulates a host of physiological processes including feeding, growth, metabolism, reproduction, immune function, behavior, and, in teleost (bony) fish, osmoregulation (Forsyth and Wallis, 2002; Bjornsson et al., 2004; Norrelund, 2005; Wood et al., 2005; Moller and Jorgensen, 2009). The actions of GH are initiated by binding to GH receptors (GHRs), which are members of the class I cytokine receptor family and which consist of a single transmembrane protein containing an extracellular ligand-binding domain and an intracellular signal transduction domain (Argetsinger and Carter-Su, 1996). In keeping with the pleiotropic actions of GH, GHRs are widely distributed among tissues of mammals and fish (Kopchick and Andry, 2000; Butler and LeRoith, 2001; Wood et al., 2005). Fish possess multiple GHR subtypes that derive from separate genes that arose through various genome duplication events during the evolution of this taxon (Reinecke et al., 2005; Fukamachi and Meyer, 2007; Li et al., 2007; Gao et al., 2011). There has emerged two distinct clades of GHRs, sometimes referred to as GHR type 1 and GHR type 2 (cf. SaeraVila et al., 2005); however, Fukamachi and Meyer (2007) suggested that type 1 GHRs should be called somatolactin receptors (SLR), but such a designation may not be applicable for all teleosts (Ozaki et al., 2006; Chen et al., 2011). Regardless, the GHR subtypes of fish are differentially expressed in a tissue-specific manner, and the individual GHR subtypes have distinct yet overlapping ligandbinding and agonist-induced regulation features (Fukada et al., 2004, 2005; Very et al., 2005; Ozaki et al., 2006; Ma et al., 2007; Norbeck et al., 2007; Reindl et al., 2009; Di Prinzio et al., 2010; Chen et al., 2011). Several studies in fish have shown that the pattern of GHR expression can be regulated by numerous nutritional, hormonal, and external environmental factors (Norbeck et al., 2007; Reinecke, 2010; Reindl and Sheridan, 2011).

Post-receptor signaling events for GH in mammalian systems are well characterized. GH binding to dimerized GHRs is followed by recruitment of JAK2 to the receptor complex and the rapid phosphorylation of GHR and JAK2; signal is propagated by activation of several other proteins and pathways, including IRS-1 and STAT5 as well as the ERK and PI3K-Akt pathways (Piwien-Pilipuk et al., 2002). Specific linkages between particular effector pathways and biological responses also are known in mammals. For example, the insulin-like metabolic effects of GH are mediated by IRS-1, whereas the proliferative effects of GH are mediated by Akt (Frago and Chowen, 2005). Far less has been reported about the mechanism(s) of GH action in fish, and virtually nothing is known about GHR subtype-effector pathway linkages. Recently, we reported that GH activates the ERK and PI3K-Akt pathways in the liver of rainbow trout and that these signal cascades play a role in GH-stimulated IGF-1 expression (Reindl et al., 2011).

In this study, we took advantage of the unique evolutionary history of teleost fish to examine the function of duplicated GHRs by establishing receptor-effector pathway linkages for the GHR subtypes. To this end, Chinese hamster ovary cells (CHO) cells were individually transfected with plasmids that contained cDNAs encoding rainbow trout GHR1 and GHR2. The examination of expressed GHRs allowed us to test the hypothesis that the GHR subtypes of teleost fish differentially activate cellular effector pathways. 


\section{MATERIALS AND METHODS MATERIALS}

All chemicals and reagents used were purchased from Sigma (St. Louis, MO, USA) unless stated otherwise. Antibodies for the phospho-specific and total (recognizing both phosphorylated and non-phosphorylated protein) forms of Akt, ERK1/2, JAK2, and STAT5, horseradish peroxidase (HRP)linked anti-rabbit IgG antibody, biotinylated molecular weight marker, anti-biotin-HRP antibody, mitogen-activated protein kinase kinase 1/2 (MEK1/2) inhibitor U0126 (MEK1 and 2 are directly responsible for the activation of ERK), PI3K inhibitor LY294002 [PI3K produces phosphatidylinositol phosphates that are critical for activation of Akt by phosphoinositidedependent kinase 1 (PDK1)], and cell lysis buffer were all obtained from Cell Signaling Technology (Beverly, MA, USA). The JAK2 inhibitor, 1,2,3,4,5,6-hexabromocyclohexane (Hex), as well as the STAT5 inhibitor, $N^{\prime}-((4-$ oxo- $4 \mathrm{H}-$ chromen-3-yl)methylene)nicotinohydrazide (Nico), and the Akt inhibitor, 1L6-hydroxymethyl-chiro-inositol-2-(R)-2-O-methyl3-O-octadecyl-sn-glycerocarbonate (Carb), were obtained from EMD Chemicals (Gibbstown, NJ, USA). Molecular weight markers were purchased from Bio-Rad Laboratories (Hercules, CA, USA).

\section{CELL LINE, PLASMID CONSTRUCTION, AND CELL TRANSFECTION}

Growth hormone receptor subtype-effector pathway linkages were studied in $\mathrm{CHO}$ cells (CHO-K1 wild type; American Type Culture Collection, Rockville, MD, USA) individually transfected with plasmids containing rainbow trout GHR1 (accession no. AY861675) and GHR2 (accession no. AY751531). CHO cells were routinely maintained in $5 \% \mathrm{CO}_{2}$ and $95 \%$ relative humidity at $37^{\circ} \mathrm{C}$ in Ham's F-12 nutrient mixture supplemented with $10 \%$ fetal calf serum (FCS), $100 \mathrm{U} / \mathrm{ml}$ penicillin, $100 \mu \mathrm{g} / \mathrm{ml}$ streptomycin, and $0.1 \%$ (v/v) fungizone (base medium). For passage, the cells were detached from the culture flasks by washing with phosphate-buffered saline (PBS) followed by brief incubation in trypsin $(0.5 \mathrm{mg} / \mathrm{ml}) /$ EDTA $(0.2 \mathrm{mg} / \mathrm{ml})$. The cells were split every 3 days. For storage, cells were resuspended in base medium containing dimethyl sulfoxide ( $10 \%$ final concentration) and frozen in liquid nitrogen.

Growth hormone receptor-encoding cDNAs were prepared from total RNA extracted from the liver of rainbow trout (Oncorhynchus mykiss) as described previously (Reindl et al., 2009). Briefly, first-strand cDNA as prepared from total RNA with the Clontech SMART ${ }^{\text {TM }}$ RACE cDNA amplification kit (Clontech Laboratories, Inc., Mountain View, CA, USA) which was then used as template for PCR using specific primers for each trout GHR-encoding cDNA (Reindl et al., 2009).

PCR products were cloned directly into the $\mathrm{pcDNA}^{\mathrm{TM}} 3.1(+)$ mammalian cell expression vector (Invitrogen Corporation, Carlsbad, CA, USA), which contains the neomycin phosphotransferase gene that confers resistance to the neomycin analog, geneticin (G418). Positive colonies were identified by agarose gel electrophoresis of restriction enzyme digests (EcoRI; Promega) of purified plasmid preparations (Wizard ${ }^{\circledast}$ Plus SV Minipreps, Promega Corporation, Madison, WI, USA). To verify the presence of the trout encoding GHR sequences, plasmid DNA (75 fmol) was sequenced with the CEQ 2000 sequencer using the Dye Terminator Cycle Sequencing Quick Start Kit (Beckman Coulter; Fullerton, CA, USA) according to the manufacturer's protocol.

Stable transfection of CHO-K1 cells was accomplished as previously described (Reindl et al., 2009). Briefly, CHO-K1 cells (ca. $4 \times 10^{5}$ ) in $0.4 \mathrm{ml}$ of ice-cold electroporation medium (Ham's F-12K without FCS or antibiotics) were combined with $10 \mu \mathrm{g}$ purified plasmid in a $0.4-\mathrm{cm}$ gene pulse cuvette. The cuvette containing the cells and DNA was placed in a BTX ECM399 (Harvard Apparatus, Inc., Holliston, MA, USA) pulse chamber, and pulsed once for $30 \mathrm{~ms}$ at $250 \mathrm{~V}$. The cells were diluted with an appropriate volume of base medium, then plated, and allowed to grow for $48 \mathrm{~h}$ before applying selection medium. The selection medium consisted of base medium with $500 \mu \mathrm{g} / \mathrm{ml}$ (final concentration) G418. The culture medium was replaced every $48-72 \mathrm{~h}$, and after 14 days in selection medium, the G418-resistant clones were subcultured for binding analysis. Three sub-clones of $\mathrm{CHO}$ cells were generated: one for each GHR-encoding cDNA (GHR1 and GHR2) and one that was transfected with vector only as a control.

\section{EXPERIMENTAL CONDITIONS}

The activation of signaling pathways was studied in transfected $\mathrm{CHO}$ cells essentially as described previously (Hagemeister et al., $2010)$. Cells $\left(1.5 \times 10^{5}\right.$ cells) were seeded into each well of a 24 well culture plate and incubated $\left(37^{\circ} \mathrm{C}, 5 \% \mathrm{CO}_{2}, 95 \%\right.$ humidity) in base medium without FCS until the cells attached firmly to the plate and reached $90 \%$ confluency (ca. $24 \mathrm{~h}$ ). After washing the cells three times with base medium, they were treated with either medium alone or with varying concentrations of salmonid GH, and incubated for the times specified in the figures under the same conditions as attachment. In combination experiments involving U0126, LY294002, Hex, Nico, or Carb, the specific inhibitor was added $2 \mathrm{~h}$ prior to hormone treatment. Following incubation, the cells were again washed three times with base medium, then lysed with $100 \mu \mathrm{l} 1 \times$ cell lysis buffer with $1 \mathrm{mM}$ phenylmethylsulfonyl fluoride (PMSF). Lysates were incubated on ice for $5 \mathrm{~min}$, refluxed 20 times with a micropipette, then centrifuged at $16000 \mathrm{~g}$ for $15 \mathrm{~min}$ at $4^{\circ} \mathrm{C}$. Protein concentration was determined on the resulting supernatant using the Bio-Rad (Hercules, CA, USA) dyebinding method. Each well of a 24-well plate, yielded ca. $2 \mathrm{mg}$ of lysate protein, was considered an individual replicate. Each experiment was repeated three times, using sub-clones from separate transfections.

\section{ANALYSIS OF [ $\left.{ }^{125}\right]$ ] -GROWTH HORMONE BINDING}

Analysis of $\left[{ }^{125} \mathrm{I}\right]$-GH binding was performed on microsomes isolated from clonal lines of CHO-K1 cells transfected with cDNAs encoding rainbow trout GHR1 or GHR2. Microsomes were isolated from $\mathrm{CHO}$ cells (ca. $12 \times 10^{6}$ cells) harvested from 6-well culture plates as described previously (Reindl et al., 2009). Binding assays were conducted using the method described by Gray et al. (1990). Salmonid GH was iodinated with $\left[{ }^{125} \mathrm{I}\right]$-sodium iodide (ICN Biomedicals, Irvine, CA, USA) as described previously (Gong et al., 2004).

\section{WESTERN BLOTTING}

Samples containing ca. $50 \mu \mathrm{g}$ of total protein were separated on a $7.5 \%$ SDS-PAGE gel and transferred to a $0.45-\mu \mathrm{m}$ nitrocellulose 
membrane (Bio-Rad Laboratories, Hercules, CA, USA) for Western analysis as previously described (Reindl et al., 2011). Membranes were visualized with enhanced chemiluminescence according to the manufacturer's instructions (GE Healthcare, Buckinghamshire, UK) followed by exposure of X-ray film (cat no. F-BX-57; Phenix Research Products, Hayward, CA, USA); the film was scanned and the bands quantified with an AlphaImager (Alpha Innotech, San Leandro, CA, USA).

\section{STATISTICS}

Quantitative data are expressed as means \pm SEM. Statistical differences were estimated by ANOVA followed by Duncan's multiplerange test. A probability level of 0.05 was used to indicate significance.

\section{RESULTS}

Two full-length cDNAs containing the entire coding regions of GHR1 and GHR2 were obtained by RT-PCR for use in the stable transfection of CHO-K1 cells. The sizes of the resulting cDNAs (1910 bp for GHR1 and 1946 bp for GHR2) matched values predicted from primer locations and were identical to those obtained previously (Reindl et al., 2009). Nucleotide sequencing verified that no random mismatching of base pairs or point mutations occurred during plasmid construction. The GHR1 cDNA encoded a 593-amino acid protein and the GHR2 cDNA encoded as 594amino acid protein, observations that were identical to those reported originally for rainbow trout GHRs (Very et al., 2005).

The functional expression of the trout GHRs was assessed by specific binding of $\left[{ }^{125} \mathrm{I}\right]-\mathrm{sGH}$ to microsomes isolated from transfected cells. CHO-K1 cells individually transfected with plasmids containing GHR1 and GHR2 cDNAs displayed significantly higher specific binding than non-transfected cells (Table 1). However, a comparable level of expression was achieved in GHR1 - and GHR2transfected cells. Typically, 25,000 cpm of labeled sGH was added to each reaction containing $50 \mu \mathrm{g}$ of microsomal protein. Under these conditions, specific binding ranged from 5.1 to $5.5 \%$ of total radioactivity added and up to $60-80 \%$ of total $\left[{ }^{125} \mathrm{I}\right]-\mathrm{sGH}$ bound; non-specific binding averaged $27.6 \pm 7.9 \%$.

Phospho-specific and total antibodies were used to study the effects of GH on activation of the ERK, PI3K/Akt, and JAK/STAT pathways via GHR1 and GHR2. GH treatment resulted in rapid phosphorylation of JAK2 in both GHR1- and GHR2-expressing cells (Figure 1). Maximum phosphorylation was observed within $5 \mathrm{~min}$ in both GHR-expressing lines; thereafter, JAK2 activation

Table 1 | Specific binding of $\left[{ }^{125} \mathrm{I}\right]$-salmonid growth hormone to microsomes isolated from Chinese hamster ovary-K1 cells individually transfected with vector only or with vector containing cDNA that encodes rainbow trout growth hormone receptor 1 (GHR1) or growth hormone receptor 2 (GHR2).

\begin{tabular}{lll}
\hline Vector only & GHR1 & GHR2 \\
\hline $137 \pm 31^{\mathrm{a}}$ & $1266 \pm 42^{\mathrm{b}}$ & $1374 \pm 53^{\mathrm{b}}$
\end{tabular}

Units of specific activity are counts per minute; data are expressed as means \pm SEM for triplicate determinations from three independent experiments. Groups with different letter are significantly different from each other $(P<0.050)$. declined, returning to levels observed in control after $10 \mathrm{~min}$. GH also stimulated phosphorylated STAT5 in both GHR-expressing lines. STAT5 activation was greatest in GHR1-expressing cells treated with $\mathrm{GH}$ for $10-30 \mathrm{~min}$, and although the degree of phosphorylation of STAT5 was less in GHR2-expressing cells than in GHR1-expressing cells, GH-stimulated significant STAT5 activation in GHR2-expressing cells 10 min after GH treatment.

Growth hormone exposure also induced ERK 1/2 phosphorylation in a time-dependent manner in both of the GHR-expressing CHO cell lines (Figure 1). For the GHR1-expressing line, maximal phosphorylation of ERK $1 / 2$ occurred within $10 \mathrm{~min}$; thereafter, pathway activation decreased, reaching control levels after $60 \mathrm{~min}$. A similar time course was observed in GHR2-expressing cells, but the extent of activation was significantly greater than that observed in GHR1-expressing cells. GH treatment also activated the PI3K/Akt pathway in a time-dependent manner in both of the GHR-expressing cell lines (Figure 1). Similar to ERK pathway activation, maximum activation of Akt in both the GHR1and GHR2-expressing cells was observed 10 min after treatment; thereafter, phosphorylation state degraded rather rapidly, but it remained slightly but significantly elevated above control levels up to 60 min after treatment.

The efficacy and potency of GH-stimulated pathway activation also was investigated (Figure 2). GH-stimulated the phosphorylation of JAK2 in a concentration-related manner with significant activation observed at a $\mathrm{GH}$ concentration as low as $1 \mathrm{ng} / \mathrm{ml}$; however, there was no difference in efficacy or potency between the GHR1- and GHR2-expressing cells (data not shown). ERK $1 / 2$ phosphorylation also was stimulated by $\mathrm{GH}$ in each of the GHR-expressing cell lines in a concentration-dependent manner (Figure 2A). However, not only was the ERK pathway activated to a greater extent (i.e., more potent) in GHR2-expressing cells than in GHR1-expressing cells, but the efficacy of GH in stimulating the ERK pathway was greater in GHR2-expressing

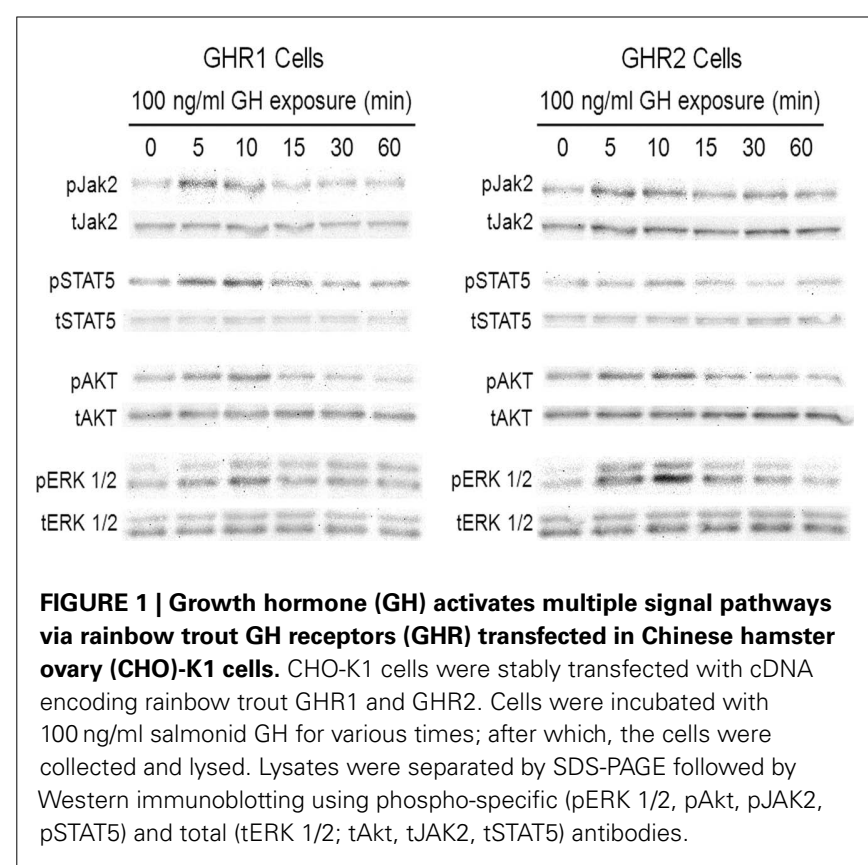


cells $\left(\mathrm{EC}_{50}=3.4 \mathrm{ng} / \mathrm{ml}\right)$ than that in GHR1-expressing cells $\left(\mathrm{EC}_{50}=85 \mathrm{ng} / \mathrm{ml}\right)$.

Growth hormone also activated Akt in a concentrationdependent manner (Figure 2B). Similar to the case with ERK activation, the efficacy of activating the PI3K/Akt pathway was greater in GHR2-expressing $\left(\mathrm{EC}_{50}=4.4 \mathrm{ng} / \mathrm{ml}\right)$ cells than in GHR1expressing cells $\left(\mathrm{EC}_{50}=22 \mathrm{ng} / \mathrm{ml}\right)$; however, there was no difference between the GHR1 cells and the GHR2 cells in the potency of $\mathrm{GH}$ to activate the PI3K/Akt pathway.

Growth hormone also stimulated phosphorylation of STAT5 in a concentration-related manner. In contrast to the action of $\mathrm{GH}$ on the activation of the ERK and PI3K/Akt pathways, however, the efficacy of GH for activating STAT5 was greater in GHR1expressing cells than in GHR2-expressing cells (Figure 2C). GHstimulated significant phosphorylation of STAT5 at $1 \mathrm{ng} / \mathrm{ml}$; the $\mathrm{EC}_{50}$ for GHR1 $(4.3 \mathrm{ng} / \mathrm{ml})$ was significantly less than the $\mathrm{EC}_{50}$ (78 ng/ml) for GHR2-expressing cells.

The linkage of GHRs to the ERK, PI3K/Akt, and/or JAK/STAT pathways was confirmed by the use of specific pathway inhibitors (Figure 3). GH-induced phosphorylation of ERK 1/2 in both the GHR1- and GHR2-expressing cells was blocked by the MEK inhibitor, U0126 (Figure 3A). Inhibition of MEK with U0126 had no effect on GH-induced activation of Akt or STAT5 in either of the GHR-expressing cells. GH- induced phosphorylation of Akt in both GHR-expressing cell lines was completely blocked by the PI3K inhibitor, LY294002. That this effect on GH-induced phosphorylation of Akt resulted from direct inhibition of Akt was confirmed by the action of the specific Akt inhibitor, Carb. Interestingly, while the MEK inhibitor had no effect on GH-stimulated Akt activation, the PI3K inhibitor and the direct Akt inhibitor partially blocked GH-stimulated ERK activation in both GHR1- and GHR2-expressing cells (Figure 3B). Neither the PI3K inhibitor nor the direct Akt inhibitor affected GH-induced phosphorylation of
STAT5 in either GHR-expressing cell line (Figure 3C). It should be noted that although a difference was observed between the two GHR-expressing cells with regard to the response of LY294002 on $\mathrm{GH}$-induced activation of ERK, this difference was reflective of the differential responsiveness of GH on ERK activation between GHR1 - and GHR2-expressing cells (Figure 3A).

Growth hormone-induced phosphorylation of STAT5 was blocked by the JAK inhibitor, Hex, in both GHR1- and GHR2expressing cells (Figure 3C). Interestingly, the JAK inhibitor also completely blocked GH-induced activation of ERK and Akt in both GHR-expressing cells. That at least some of the effects of STAT blockade on $\mathrm{GH}$-induced activation were direct rather than mediated through other pathways was confirmed by the effects of the specific STAT5 inhibitor, Nico; the STAT inhibitor had no effect on GH-induced activation of ERK or Akt in either GHR-expressing cell line (Figures 3A,B).

\section{DISCUSSION}

Understanding the molecular basis of $\mathrm{GH}$ action in teleost fish is complicated by the existence of multiple GHR subtypes that display both distinct and overlapping ligand-binding characteristics (Fukada et al., 2004, 2005; Very et al., 2005; Ozaki et al., 2006; Fukamachi and Meyer, 2007; Li et al., 2007; Ma et al., 2007; Chen et al., 2011; Gao et al., 2011). In this study, we took advantage of stably transfected $\mathrm{CHO}-\mathrm{K} 1$ cells to establish for the first time receptoreffector pathway linkages for teleost GHRs. The transfected CHOK1 cells synthesized rainbow trout GHRs mRNAs and correctly targeted the receptor proteins to the cell surface; binding analysis confirmed that both of the GHR-expressing cell lines (GHR1 and GHR2) were functional and bound $\left[{ }^{125} \mathrm{I}\right]-\mathrm{GH}$-observations that were consistent with our previous results in which expressed rainbow trout GHR1 and GHR2 bound $\left[{ }^{125} \mathrm{I}\right]-\mathrm{GH}$ with high affinity (Reindl et al., 2009). The present findings demonstrated linkages
A ERK activation

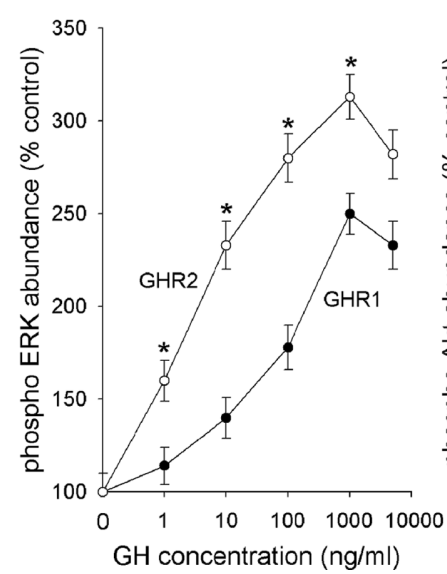

B Akt activation

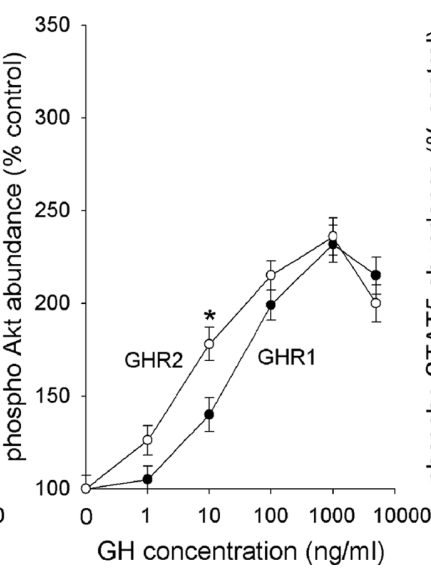

C STAT5 activation

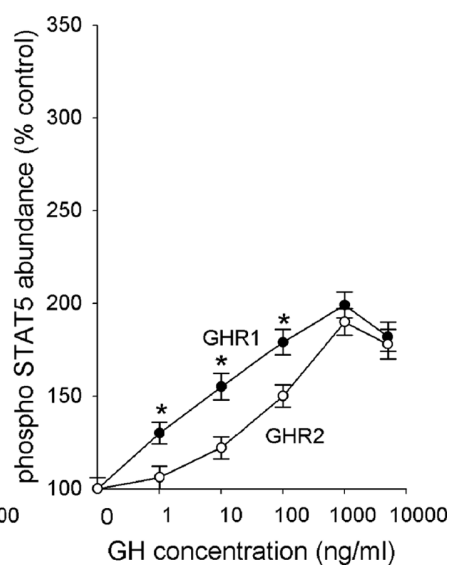

FIGURE 2 | Growth hormone receptors (GHR) subtypes differentially activate (A) ERK, (B) Akt, and (C) STAT5. CHO-K1 cells were stably transfected with cDNA encoding rainbow trout GHR1 and GHR2. Cells were incubated with various concentrations of salmonid $\mathrm{GH}$ for $10 \mathrm{~min}$ (control is $0 \mathrm{ng} / \mathrm{ml}$ ); after which time, the cells were collected and lysed. Lysates were separated by SDS-PAGE followed by Western immunoblotting using phospho-specific (pERK 1/2, pAkt, pJAK2, pSTAT5) and total (tERK 1/2; tAkt, tJAK2, tSTAT5) antibodies. Data are expressed as percentage of control and are presented as means \pm SEM $(n=8)$ of blots quantified with a digital imaging system; ${ }^{*}$ designates groups that are significantly different from each other $(P<0.05)$. 


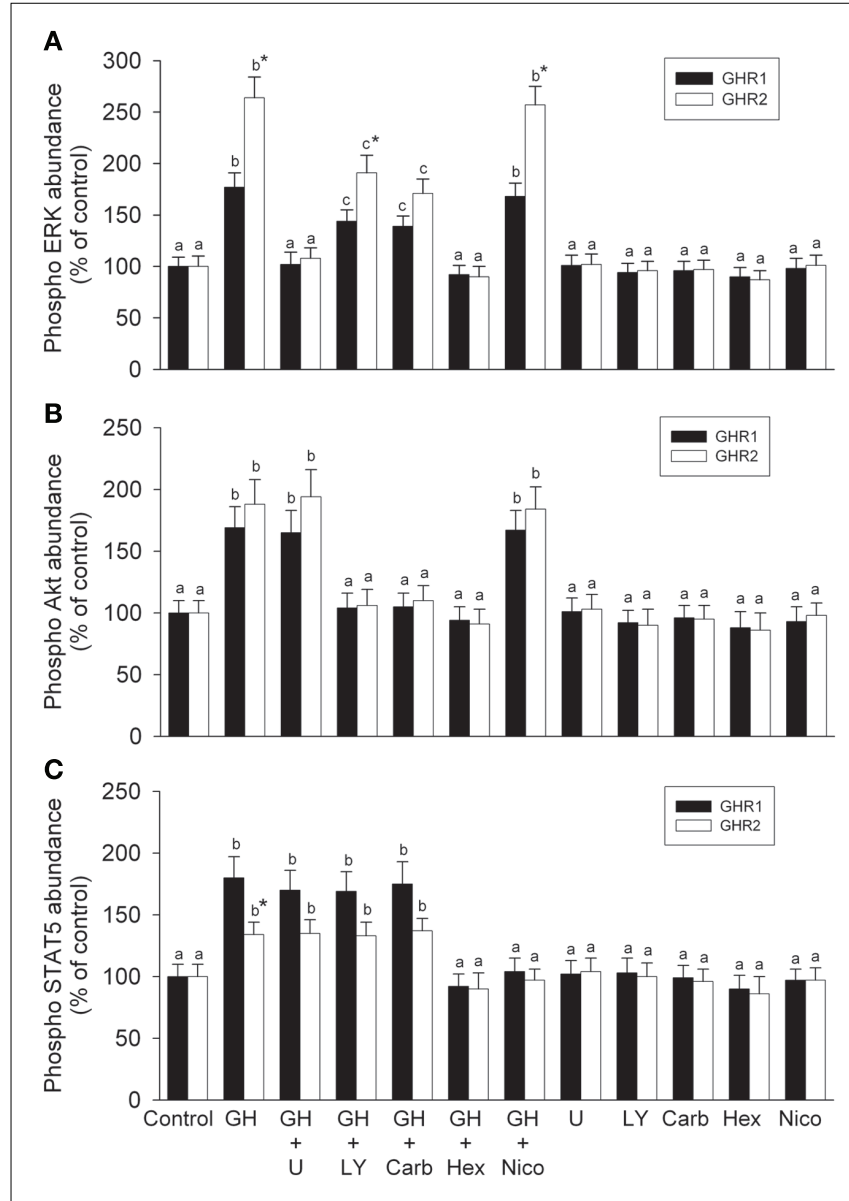

FIGURE 3 | Effects of pathway blockade on growth hormone-induced activation of (A) ERK, (B) Akt, and (C) STAT5. CHO-K1 cells were stably transfected with cDNA encoding rainbow trout GHR1 and GHR2. Transfected cells were pretreated with or without specific inhibitors [10 $\mu \mathrm{M}$ of the MEK inhibitor, U0126; $20 \mu \mathrm{M}$ of the PI3K inhibitor, LY294002 (LY); $25 \mu \mathrm{M}$ of the Akt inhibitor, 1 L6-hydroxyymethyl-chiro-inositol-2-(R)-2-Omethyl-3-O-octadecyl-sn-glycerocarbonate (Carb); $200 \mu \mathrm{M}$ of the STAT5 inhibitor, N'-((4-oxo-4H-chroen-3-yl)methylene)nicotinohydrazide (Nico); and $50 \mu \mathrm{M}$ of the JAK2 inhibitor, 1,2,3,4,5,6-hexabromocyclohexane (Hex)] for $2 \mathrm{~h}$, then treated with or without $100 \mathrm{ng} / \mathrm{ml}$ growth hormone $(\mathrm{GH})$ for $10 \mathrm{~min}$ (control is $0 \mathrm{ng} / \mathrm{ml} \mathrm{GH}$ ); after which time, the cells were collected and lysed. Cell lysates were separated by SDS-PAGE followed by Western immunoblotting using phospho-specific (pERK1/2, pAkt, or pSTAT) and total (tERK1/2, tAkt, or tSTAT) antibodies. Data are expressed as percentage of control and are presented as means $\pm \operatorname{SEM}(n=8)$. For a given GHR subtype, groups with different letters are significantly different from each other $(P<0.05)$; * designates a significant difference $(P<0.05)$ between subtypes within a given treatment.

between fish GHRs and the JAK-STAT, ERK, and PI3K-Akt pathways and provide insight into the molecular mechanisms by which GH may elicit specific physiological effects in target cells.

Rainbow trout GHRs activate the ERK signaling pathway. This conclusion is supported by the observation that GH-stimulated ERK 1/2 phosphorylation in both of the GHR-expressing cell lines. Furthermore, blockade of the ERK pathway with the MEK inhibitor, U0126, prevented GH-induced phosphorylation of ERK $1 / 2$. These findings are consistent with previous studies in native

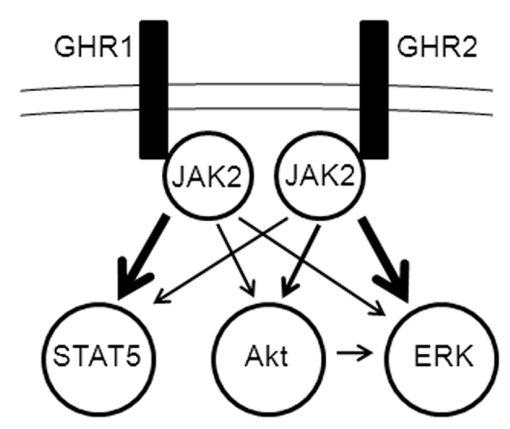

FIGURE 4 | Model of differential activation of signaling pathways by growth hormone receptor (GHR) subtypes. JAK2 activation is essential for propagation of signaling from both GHR1 and GHR2 to the ERK, PI3K/Akt, and STAT5 pathways (details of pathway elements are omitted for simplicity). Cross-talk occurs between the ERK and PI3K/Akt pathways, possibly through Akt activation of c-Raf in the ERK pathway.

systems of fish in which GH-induced ERK activation in hepatocytes incubated in vitro (Reindl et al., 2011). The involvement of ERK in conducting GH intracellular signaling also has been studied in mammalian systems (Piwien-Pilipuk et al., 2002).

Rainbow trout GHRs also activate the PI3K/Akt pathway. This conclusion is supported by the observation that in both GHRexpressing cell lines, $\mathrm{GH}$-induced the phosphorylation of Akt, a signaling element downstream of PI3K. In addition, the PI3K inhibitor, LY294002, blocked GH-stimulated Akt phosphorylation. That GH-stimulated activation of Akt was dependent on PI3K was confirmed by the observation that the Akt-specific inhibitor, Carb, blocked Akt activation to the same extent as the PI3K inhibitor, LY294002. These findings are consistent with previous studies in trout that showed that GH activates Akt in liver cells in vitro (Reindl et al., 2011). The PI3K-Akt pathway also is known to mediate the action of $\mathrm{GH}$ in mammalian systems (Argetsinger and Carter-Su, 1996).

There is cross-talk between the ERK and PI3K-Akt pathways. This notion is supported by the observation that inhibition of both PI3K (via LY294002) and Akt directly (via Carb) partially blocked $\mathrm{GH}$-induced phosphorylation of ERK. That the activation of ERK was partially dependent on Akt and not vice versa was supported by the observation that ERK pathway blockade by U0126 had no effect on Akt activation in either GHR-expressing cell line. Crosstalk between the PI3K/Akt pathway and ERK pathway has been shown in mammals, with c-Raf serving as a nexus between the two pathways and establishing and PI3K-c-Raf-MEK-ERK cascade (Zimmermann and Moelling, 1999; Reusch et al., 2001). It should be noted that the because the Akt and PI3K inhibitors knocked down some but not all GH-induced activation of ERK, upstream elements other than PI3K may serve to activate the c-Raf-MEK-ERK cascade.

Rainbow trout GHRs activate the JAK-STAT signaling pathway in addition to the ERK and PI3K-Akt pathways. This conclusion is supported by the observation that GH-stimulated phosphorylation of JAK2 and STAT5 in both GHR-expressing cell lines. Moreover, the JAK2-specific inhibitor, Hex, and the STAT5 specific inhibitor, Nico, prevented GH-stimulated phosphorylation of 
STAT5 in both GHR-expressing cell lines. These findings are consistent with previous studies in native systems of fish in which $\mathrm{GH}$-induced activation of JAK2 and STAT5 in hepatocytes (Reindl et al., 2011) as well as with studies in mammalian systems (CarterSu et al., 2000; Waters et al., 2006). That JAK2 is most proximal to GHR and is critical for signal propagation through either the ERK or PI3K/Akt pathways was supported by several observations. Although the ERK pathway inhibitor, U0126, the PI3K inhibitor, LY294002, and the Akt inhibitor, Carb, had no effect on the phosphorylation of STAT5, the JAK2 inhibitor, Hex, completely inhibited ERK, and Akt activation in addition to inhibition of STAT5. These findings are consistent with the observations that JAK2 activation is the initial step in GH signal transduction in mammalian systems and that activation of the ERK and PI3K pathways are downstream of JAK (Piwien-Pilipuk et al., 2002; Waters et al., 2006).

The current findings indicate that there are significant differences in the efficacy of the two rainbow trout GHR subtypes to activate ERK, PI3K-Akt, and STAT pathways. The ERK and the PI3K-Akt pathways were preferentially activated through rainbow trout GHR2, whereas STAT5 was preferentially activated through rainbow trout GHR1. Previous studies have shown that the ERK and PI3K-Akt pathways differentially link to subtypes of the somatostatin receptors of fish and mammals (Charland et al., 2001; Hagemeister et al., 2010). The molecular basis(es) for these preferentially linkages is(are) not known, but it(they) probably result(s) from structural differences among the receptor subtypes. In the case of the rainbow trout GHRs, despite their overall similarity (85.5\% amino acid identity between GHR1 and GHR2), there are several notable differences in the intracellular domain, particularly the Box 1 region (Very et al., 2005) - a region that has been found to play an important role in coupling to cellular effector pathways in mammals (Carter-Su et al., 2000; Kopchick and Andry, 2000). A model of the mechanisms activated by $\mathrm{GH}$ through rainbow trout GHRs is depicted in Figure 4. In this model, the binding of GH to GHR initiates a progression of events, from activation of JAK2 to differential propagation via ERK, PI3K-Akt, and STAT5. It should be noted that the cross-talk between the Akt and ERK pathways must be governed in some manner in order to explain the observed differential activation of Akt by GHR and of ERK by GHR2.

\section{REFERENCES}

Argetsinger, L. S., and Carter-Su, C. (1996). Mechanism of signaling by growth hormone receptor. Physiol. Rev. 76, 1089-1107.

Bjornsson, B. T., Johansson, V., Benedet, S., Einarsdottir, I. E., Hildahl, J., Agustsson, T., and Jonsson, E. (2004). Growth hormone endocrinology of salmonids: regulatory mechanisms and mode of action. Fish Physiol. Biochem. 27, 227-242.

Butler, A. A., and LeRoith, D. L. (2001). Control of growth by the somatotropic axis: growth hormone and the insulin-like growth factors have related and independent roles. Ann. Rev. Physiol. 63, 141-164.

Carter-Su, C., Rui, L., and Herrington, J. (2000). Role of the tyrosine kinase JAK2 in signal transduction by growth hormone. Pediatr. Nephhrol. 14, 550-557.

Charland, S., Boucher, M. J., Houde, M., and Rivard, N. (2001). Somatostatin inhibits Akt phosphorylation and cell cycle entry, but not p42/p44 mitogen-activated protein (MAP) kinase activation in normal and tumoral pancreatic acinar cells. Endocrinology 142, 121-128.

Chen, M., Huang, X., Yuen, D. S. H., and Cheng, C. H. K. (2011). A study on the functional interaction

The observed differential linkages to cellular effector pathways provide some insight into the functional significance of GHR subtypes in teleost fish. By GH binding to one or the other forms of GHR in native cells, a specific complement of signaling pathways would be activated. While there are no direct data in fish regarding linkages between specific pathways and biological responses, there are studies in mammals showing that IRS-1 mediates the insulin-like metabolic effects of GH and that Akt mediates the proliferative effects of GH (Frago and Chowen, 2005). The situation is complicated in fish in that native cells often express a mixture of GHR subtypes (Reinecke et al., 2005; Saera-Vila et al., 2005; Very et al., 2005; Ozaki et al., 2006; Fukamachi and Meyer, 2007; Li et al., 2007; Ma et al., 2007; Gao et al., 2011). However, there is some evidence in fish that the GHR subtypes link to different actions. Using a reporter system in CHO cells, Jiao et al. (2006) showed that GH binding to sea bream (sb) GHR1 and sbGHR2 activated transcription of Spi 2.1 and $\beta$-casein, whereas sbGHR1 but not sbGHR2 mediated $\mathrm{GH}$ activation of the c-fos promoter. In addition, the pattern of expression of GHR subtypes in native cells differs with nutrition, stage of sexual maturation, and the nature of osmotic environment in which the fish resides (seawater vs. fresh water; Saera-Vila et al., 2005; Ma et al., 2007; Norbeck et al., 2007; Pierce et al., 2007; Poppinga et al., 2007; Raine et al., 2007; Di Prinzio et al., 2010). In light of our current findings as well previous findings by us and others regarding differential binding characteristics of GHR (Fukada et al., 2004, 2005; Ozaki et al., 2006; Reindl et al., 2009; Chen et al., 2011), it is reasonable to suggest that the actions of GH in teleost fish depend on the abundance of particular GHR subtypes as well as on the signal pathways that are expressed in target cells under given developmental/physiological conditions.

\section{ACKNOWLEDGMENTS}

We thank Andrea Hanson, Lincoln Martin, Lindsey Norbeck, Katie Reindl, and Chad Walock for their technical assistance and valuable discussions. We are grateful to Prof. Akiyoshi Takahashi and Dr. Shunsuke Moriyama (Kitasato University, Japan) for providing salmonid GH. The research was supported by a grant from the National Science Foundation, USA (IOS-0920116) to Mark A. Sheridan.

between the GH/PRL family of polypeptides with their receptors in zebrafish: evidence against GHR1 being the receptor for somatolactin. Mol. Cell. Endocrinol. 337, 114-121.

Di Prinzio, C. M., Botta, P. E., Barriga, E. H., Rios, E. A., Reyes, A. E., and Arranz, S. E. (2010). Growth hormone receptors in zebrafish (Danio rerio): adult and embryonic expression patterns. Gene Expr. Patterns 10, 214-225.

Forsyth, I. A., and Wallis, M. (2002). Growth hormone and prolactin molecular and functional evolution. J. Mammary Gland Biol. Neoplasia 7 , 291-312.
Frago, L. M., and Chowen, J.A. (2005). Basic physiology of the growth hormone/insulin-like growth factor axis. Adv. Exp. Med. Biol. 567, 1-25.

Fukada, H., Ozaki, Y., Pierce, A. L., Adachi, S., Yamauchi, K., Hara, A., Swanson, P., and Dickhoff, W. W. (2004). Salmon growth hormone receptors: molecular cloning, ligand specificity, and response to fasting. Gen. Comp. Endocrinol. 139, 61-71.

Fukada, H., Ozaki, Y., Pierce, A. L., Adachi, S., Yamauchi, K., Hara, A., Swanson, P., and Dickhoff, W. W. (2005). Identification of the salmon somatolactin receptor, a new member of the cytokine receptor family. Endocrinology 146, 2354-2361. 
Fukamachi, S., and Meyer, A. (2007). Evolution of receptors for growth hormone and somatolactin in fish and land vertebrates: lessons from the lungfish and sturgeon orthologues. J. Mol. Evol. 65, 359-372.

Gao, F.-Y., Lu, M.-X., Ye, X., Huang, Z.-H., Wang, H., Zhu, H.-P., and Yang, L.-P. (2011). Identification and expression analysis of two growth hormone receptors in zanzibar tilapia (Oreochromis hornorum). Fish Physiol. Biochem. 37, 553-565.

Gong, J.-Y., Kittilson, J. D., Slagter, B. A., and Sheridan, M. A. (2004). The two subtype 1 somatostatin receptors of rainbow trout, Tsst1A and Tsst1B, possess both distinct and overlapping ligand binding and agonistinduced regulation features. Comp. Biochem. Physiol. B Biochem. Mol. Biol. 138, 295-303.

Gray, E. S., Young, G., and Bern, H. A. (1990). Radioreceptor assay for growth hormone in coho salmon (Oncorhynchus kisutch). J. Exp. Zool. 256, 290-296.

Hagemeister, A. L., Kittilson, J. D., Bergan, H. E., and Sheridan, M. A. (2010). Rainbow trout somatostatin receptors subtypes SSTR1A, SSTR1B, and SSTR2 differentially activate the extracellular signalregulated kinase and phosphatidylinositol 3-kinase signaling pathways in transfected cells. J. Mol. Endocrinol. 45, 317-327.

Jiao, B., Huang, X., Chan, C. B., Zhang, L., Wang, D., and Cheng, C. H. K. (2006). The co-existence of two growth hormone receptors in teleost fish and their differential signal transduction, tissue distribution, and hormonal regulation of expression in sea bream. J. Mol. Endocrinol. 36, 23-40.

Kopchick, J. J., and Andry, J. M. (2000). Growth hormone (GH), GH receptor and signal transduction. Mol. Genet. Metab. 71, 293-314.

Li, Y., Liu, X., Zhang, Y., Zhu, P., and Lin, H. (2007). Molecular cloning, characterization and distribution of two types of growth hormone receptor in orange-spotted grouper (Epinephelus coioides). Gen. Comp. Endocrinol. 152, 111-122.

Ma, X., Liu, X., Zhang, Y., Zhu, P., Ye, W., and Lin, H. (2007). Two growth hormone receptors in Nile tilapia (Oreochromis niloticus): molecular characterization, tissue distribution and expression profiles in the gonad during the reproductive cycle. Comp. Biochem. Physiol. B Biochem. Mol. Biol. 147, 325-339.

Moller, N., and Jorgensen, J. O. L. (2009). Effects of growth hormone on glucose, lipid, and protein metabolism in human subjects. Endocr. Rev. 30, 152-177.

Norbeck, L. A., Kittilson, J. D., and Sheridan, M. A. (2007). Resolving the growth-promoting and metabolic effects of growth hormone: differential regulation of GH-IGFI system components. Gen. Comp. Endocrinol. 151, 332-341.

Norrelund, H. (2005).The metabolic role of growth hormone in humans with particular reference to fasting. Growth Horm. IGF Res. 15, 95-122.

Ozaki, Y., Fukada, H., Kazeto, Y., Adachi, S., Hara, A., and Yamauchi, K. (2006). Molecular cloning and characterization of growth hormone receptor and its homologue in the Japanese eel (Anguilla japonica). Comp. Biochem. Physiol. B Biochem. Mol. Biol. 143, 422-431.

Pierce, A. L., Fox, B. K., Davis, L. K., Visitacion, N., Kitahashi, T., Hirano, T., and Grau, E. G. (2007). Prolactin receptor, growth hormone receptor, and putative somatolactin receptor in Mozambique tilapia: tissue specific expression and differential regulation by salinity and fasting. Gen . Comp. Endocrinol. 154, 31-40.

Piwien-Pilipuk, G., Huo, J. S., and Schwartz, J. (2002). Growth hormone signal transduction. J. Pediatr. Endocrinol. Metab. 15, 771-786.

Poppinga, J., Kittilson, J., McCormick, S. D., and Sheridan, M. A. (2007). Effects of somatostatin on the growth hormone-insulin-like growth factor-1 axis and seawater adaptation of rainbow trout
(Oncorhynchus mykiss). Aquaculture 273, 313-319.

Raine, J. C., Hua, K., Bureau, D. P., Vijayan, M. M., and Leatherland, J. F. (2007). Influence of ration level and rearing temperature on hepatic GHR1 and GHR2, and hepatic and intestinal TR $\alpha$ and TR $\beta$ gene expression in late stages of rainbow trout embryos. J. Fish Biol. 71, 148-162.

Reindl, K. M., Kittilson, J. D., Bergan, H. E., and Sheridan, M. A. (2011) Growth hormone-stimulated insulin-like growth factor-1 expression in rainbow trout (Oncorhynchus mykiss) hepatocytes is mediated by ERK, PI3K-AKT, and JAK-STAT. Am. J. Physiol. 301, R236-R243.

Reindl, K. M., Kittilson, J. D., and Sheridan, M. A. (2009). Differential ligand binding and agonist-induced regulation characteristics of the two rainbow trout $\mathrm{GH}$ receptors, GHR1 and GHR2, in transfected cells. $J$. Endocrinol. 202, 463-471.

Reindl, K. M., and Sheridan, M. A. (2011). Peripheral regulation of the growth hormone/insulin-like growth factor system in fish and other vertebrates. Aquac. Int. (in press).

Reinecke, M. (2010). Influences of the environment on the endocrine and paracrine fish growth hormoneinsulin-like growth factor-I system. J. Fish. Biol. 76, 1233-1254.

Reinecke, M., Bjornsson, B. T., Dickhoff, W. W., McCormick, S. D., Navarro, I., Power, D. M., and Gutierrez, J. (2005). Growth hormone and insulin-like growth factors in fish: where we are and where to go. Gen. Comp. Endocrinol. 142, 20-24.

Reusch, H. P., Zimmermann, S., Schaefer, M., Paul, M., and Moelling, K. (2001). Regulation of Raf by Akt controls growth and differentiation in vascular smooth muscle cells. $J$. Biol. Chem. 276, 33630-33637.

Saera-Vila, A., Calduch-Ginner, J.-A. and Pérez-Sánchez, J. (2005). Duplication of growth hormone receptor (GHR) in fish genome: gene organization and transcriptional regulation of GHR type I and type
II in gilthead sea bream (Sparus aurata). Gen. Comp. Endocrinol. 142, 193-303.

Very, N. M., Kittilson, J. D., Norbeck, L. A., and Sheridan, M. A. (2005) Isolation, characterization, and distribution of two cDNAs encoding for growth hormone receptor in rainbow trout (Oncorhynchus mykiss). Comp. Biochem. Physiol. B Biochem. Mol. Biol. 140 615-628.

Waters, M. J., Hoang, H. N., Fairlie, D. P., Pelekanos, R. A., and Brown, R. J. (2006). New insights into growth hormone action. J. Mol. Endocrinol. $36,1-7$.

Wood, A. W., Duan, C., and Bern, H. A. (2005). Insulin-like growth factor signaling in fish. Int. Rev. Cytol. 243, 215-285.

Zimmermann, S., and Moelling, K. (1999). Phosphorylation and regulation of Raf by Akt (protein kinase B). Science 286, 1741-1744.

Conflict of Interest Statement: The authors declare that the research was conducted in the absence of any commercial or financial relationships that could be construed as a potential conflict of interest.

Received: 01 June 2011; accepted: 26 August 2011; published online: 20 September 2011.

Citation: Kittilson JD, Jones E and Sheridan MA (2011) ERK, Akt, and STAT5 are differentially activated by the two growth hormone receptor subtypes of a teleost fish (Oncorhynchus mykiss). Front. Endocrin. 2:30. doi: 10.3389/fendo.2011.00030

This article was submitted to Frontiers in Experimental Endocrinology, a specialty of Frontiers in Endocrinology.

Copyright (c) 2011 Kittilson, Jones and Sheridan. This is an open-access article subject to a non-exclusive license between the authors and Frontiers Media $S A$, which permits use, distribution and reproduction in other forums, provided the original authors and source are credited and other Frontiers conditions are complied with. 